\title{
Participation, Communication and Innovation: Thinking About the International AIDS Vaccine Initiative
}

\author{
Joanna Chataway and James Smith
}

\begin{abstract}
1 Introduction
Science, technology and innovation are currently major areas of investment for development agencies and the subject of numerous development initiatives. One of the key issues often discussed in relation to efforts to create science for development is who should make decisions about new technologies and innovation and whether more or less participation is needed.
\end{abstract}

Participation can be viewed in two ways. As a mechanism to ensure increased democracy in decision-making about development and as a way of achieving other social and economic development goals, economic growth, or better ways of delivering health and education for instance. These two approaches can be thought of as an 'entitlement view' on the one hand and a 'productivity view' on the other (Mosse 2005). ${ }^{1}$ Both views are widely used and both have very substantial literatures and theoretical constructs that underpin them.

Participation is drawn into debates about technological innovation and debates about science and technology in many ways in a wide variety of settings. The quality and purpose of participation is often contentious. In particular, discussion about efforts to create forms of direct democracy or participative democracy in relation to science and technology has been bitterly contested and voluminous (Irwin and Wynne 2004; Leach et al. 2005; Jasanoff 2007). Recent work highlights problems in trying to use 'participation' as a wideranging decision-making tool about technologies in the abstract. Various authors argue strongly against advocating the use of participative techniques simply on the grounds that they lead to increased democracy (Tait 2004). Using the example of the GM Nation debate in the UK, Tait argues that 'participation' and instances of 'deliberative democracy' are often smokescreens for special issue groups to exert control. This theme is also dealt with in relation to biotechnology debates by Taverne (2005). Other work has highlighted instances where participation is used to legitimate science and technology-based development projects and in communication to funders but has not delivered significant opportunities for broader engagement over the way those projects are developed and run (Chataway and Smith 2006). The more general point here is that participation can involve changed epistemologies in relation to knowing what different groups feel and need but may well not be democratic or involve substantial institutional change. This is an argument articulated elegantly by Mohan (2007). Participation events do not necessarily represent significant advances in deliberative democracy. They often fail in terms of both productivity and entitlement.

Detailed investigation into the way participation is encouraged and used is key to more nuanced perspectives regarding the value of participation. This article is a tentative and exploratory attempt to think about how we can develop tools to evaluate participation in the context of broader institutional development in the area of science, technology and innovation rather than as one-off 'events', smokescreens or vehicles for legitimation.

The article draws on a case study of a high-profile initiative which has communication and participation at its core. The International AIDS Vaccine Initiative $(I \mathrm{IVI})$ seeks to develop AIDS vaccines while building 
demand for vaccines as a means to ensure sufficient funds exist to purchase vaccines as they are developed to market. IAVI is rooted in traditions of innovation and market chain approaches, aware of the dangers of technology-led strategies and keen to engage a wide variety of stakeholders both in the development of an effective vaccine and in widespread distribution of an accepted and popular vaccine. We argue that IAVI views participation as central to its communications efforts and explain why this is the case.

This article suggests that analysis of participation and communication might benefit from revisiting Albert Hirschman's ideas of exit, voice and loyalty. We give some suggestions of how this framework might be used to explore institutional aspects of participation and communications in the case of IAVI.

\section{Participation and engagement: creating 'voice'} Ideally the 'entitlement view' and the 'productivity view' of participation become one and the same. More participation, more inclusion, more accountability leads to improved performance and 'better development' in the short run and with regard to particular projects, and lays the basis for better decision-making and a more solid grounding for development in the longer term. That can and does happen. But of course it does not always happen. Entitlement and productivity as a result of participation can happen independently of each other or not at all.

Development, as a process of change, has conflict at its heart. One way of looking at participation is as a channel for voicing dissent - it can be seen as a way of ensuring engagement even in the case of disagreement. Hirschman (1970) offered a conceptual framework for understanding the value of participation and engagement in his seminal work, 'Exit, Voice and Loyalty': Responses to decline in firms, organisations and states. Hirschman's is an explicit attempt to create an interdisciplinary understanding of how effective institutions get created and draws on concepts and tools from economics and politics. Economists tend to value 'exit', the ability to choose and reject options to buy products and services, as a way of promoting competition and better institutions. But not all situations lend themselves to this market-based mechanism and Hirschman posits 'voice' and engagement as another mechanism, rooted in the traditions of politics and political science as an equally important way to advance institutional development. Put very crudely, the opportunity to participate, to engage, gives people the opportunity to voice their opinions and, if the institutional conditions exist, and given a degree of loyalty to the institution, firm or initiative, improvement can and often does result from participation. A balance between opportunities for 'voice', possibilities for 'exit' and efforts to secure 'loyalty' are fundamentals in creating effective organisations. Some organisations and exits are more responsive and susceptible to either exit or voice, in part depending on the degree of loyalty which people attach to them (firms for instance are more generally susceptible to exit than political parties), but both have crucial roles to play in improving different kinds of organisations and institutions.

The process of creating conditions for engagement and 'voice', as thought by Hirschman, involves both 'productivity' and 'entitlement' aspects of participation. His thoughts are echoed in more recent literature on innovation. For example, the idea of 'feedback' between researchers, producers, users and consumers has replaced the 'linear model' as a mantra behind which innovation scholars and policymakers now line up. This is one articulation of the need for voice and much of the innovation systems literature deals with the value of interaction and participation in this sense (Lundvall 1992; Hall 2005).

This is different from the idea of having structured, organised forms of participation, and we suggest that those types of activities are a necessary or even sufficient condition for technological development to take place and have positive impacts. Things are always contingent on context and the right innovation in the right place at the right time can unlock development benefits in a way that any number of participative exercises cannot. In cases where the market operates or where choice exists, 'exit' in Hirschman's terms, provides an effective way of determining the popularity and desirability of what an organisation produces and can bring about positive impacts. For example, there were very few participation exercises around the introduction of mobile phones in developing countries, and little suggestion that participation exercises are necessary and yet people in Africa and elsewhere have adopted this technology rapidly and it is having multiple impacts on the way in which people are able to 
conduct business and organise life. In these cases, where the institutional infrastructure allows for choice and there is some degree of competition, the threat of exit (people voting with their purchasing power) may be sufficient to inspire improvements in product delivery and services.

Still, as Hirschman points out, in many institutional contexts in both developing and developed countries, market institutions may not be well developed or not appropriate and different organisational forms need to be established to facilitate improvement. It is here that 'voice' needs to be thought about. This analysis is critically relevant to improving science and technology-based innovation in developing countries. Creating effective participation and engagement in these circumstances is difficult and challenging but often essential to success. Our understanding of what 'works', of what is legitimate and of what constitutes good practice remains relatively weak. We need to develop more refined perspectives on participation, different modes of participation and their relationship to institutional reform, citizenship and democratic practices.

\section{Participation, communication and innovation systems}

One way in which to refine thinking about participation might be to clarify its relationship to communication strategies. Without communication, participation is redundant. However, the broader communications flows between organisations and institutions are often ignored in studies of participation. As Hickey and Mohan have pointed out, participation is often viewed as a contained event rather than as part of broader political developments and in terms of a political channel within and between organisations (Hickey and Mohan 2004; Mohan 2007)

We suggest that looking at the relationship between communication and participation strategies of a particular innovation and development initiative is useful for the following two reasons:

1 Most development interventions have a purposive as well as normative aspect. They are about participation as 'productivity' as well as 'entitlement'; understanding that in most cases participation is used as a device to communicate the usefulness of certain approaches or ideas as well as to listen and learn and be led by local ideas, is a more accurate picture of the majority of development interventions.

2 The extent to which participation is embedded in communication strategies and channels of communication within and between organisations is vital to understanding the limits and/or potential of participation. If grassroots participation is viewed as an isolated event rather than an integral part of communication flows it is much less significant than if incorporated into an approach which views it as an ongoing effort to adjust power relations.

Thus talking about communication strategies in relation to development initiatives acknowledges that there is an internal purpose and agenda which run alongside and is intimately aligned to participation activities. It also helps us to see participation as part of broader organisational and institutional set-ups. Adopting this line of thought, a number of questions might be asked of particular initiatives and organisations which involve participation exercises, including the following: Is participation a genuine attempt to let grassroots and other influences shape the strategy of an organisation (are communication channels refigured around participation)? This could be thought of as 'communication for participation'. Or is participation a way of trying to create legitimacy without substantially altering the broader agenda? This could be thought of as 'participation for communication'. Thinking about a system and institutions very broadly, participation then may result in shaping the organisation to work in a more systemic way, or it may influence the system to the needs and agendas of the organisation. It may of course do both of these things.

More general discussions and frameworks for looking at participation are certainly essential but there are particular ways in which they configure around issues of science, technology and innovation. Innovation systems' thinking constitutes another body of work that can help to situate participative activities in the broader context of institutional development.

Innovation systems' thinking is predicated on the idea that innovation requires networks, linkages and partnerships. It is predominantly routed in a 'productivity view' of participation. Andy Hall et al. (2001: 794) describe an innovation system as follows: 
At its heart lies the contention that change - or innovation - results from and is shaped by the system of organizations and institutions (in the rules, norms and conventions sense) in particular locations and points in time. An innovation system includes organizations involved with research and the application and adaptation of research findings, as well as intermediary organizations that promote knowledge transfer.

The great contribution made by innovation systems is that it forces us to think about technologies and innovation in relation to the institutional structures which they relate to. $A$ whole set of interesting questions are being asked about how particular innovations occur within systems and what kind of interactions are needed to achieve successful innovation. How are sectoral and national systems constructed as the result of multiple innovationbased initiatives which forge their own microsystems? These questions that try and relate the micro and macro through case studies of new innovations are the subject of interesting work by evolutionary economists such Metcalfe and others such as Hall (Metcalfe 2005; Mina et al. 2005; Hall 2005).

Careful case study analysis in this work moves us away from abstract consideration of participation and innovation systems and injects the analysis with the messy reality of 'trying to get things done'. 'Trying to get things done' is not simply about systems, innovation or participation, it is also an entirely political activity; something that the abstraction of innovation systems approaches does not engage with. Here, analysis mainly relates to 'productivity' views of participation but what is interesting is that often the distinction between productivity and entitlement views begin to break down. Small farmers organised into groups and for training and enhancement of technical skills and advice about growing vitamin Arich sweet potatoes gain capacity to intervene in decision-making and 'voice' in multiple ways (Chataway and Smith 2007). These complex relationships between the more instrumentalist approaches of innovation systems and the creation of broader capacities are not well understood or studied. Our perspective in this article is that one angle from which to view these complex relationships is from the perspective of how participation is or is not integrated into communication strategies and how concepts of exit, voice and loyalty can shed light on broader dynamics. With this in mind, we now briefly look at IAVI.

\section{The International AIDS Vaccine Initiative (IAVI): innovation driven by communication} IAVI is a large international not-for-profit publicprivate partnership devoted to creating a preventative AIDS vaccine. Its headquarters are in New York and it works in approximately 23 countries, building local research capacity, primarily to undertake local vaccine trials, and building awareness and 'demand' for an AIDS vaccine. Although it is a long way from achieving its core goal of creating and distributing a vaccine, IAVI has achieved three main aims. First, it has raised large sums of money, over US\$340 million by 2006. This money has been used to fund the development of promising vaccine candidates and to raise awareness about HIV/AIDS and the need for a vaccine. Second, and intimately connected to the first, it has created widespread awareness of the potential impact of vaccines and the role that cutting edge science and technology can play in the fight against AIDS in developing countries (Skolnik 2003). IAVI has put forward the possibility of an HIV/AIDS vaccine, and awareness of the need for very considerable investment, on the agenda of every bilateral donor. Third, it has created capacities in developing countries both to carry out advocacy in relation to HIV/AIDS and also to participate in the actual development of vaccine and in carrying out clinical trials.

Communication is essential to IAVI and a diverse set of communications activities, from grassroots advocacy to high level public relations are core business. For example, in 2000 a photograph of Seth Berkeley, IAVI's chief executive officer (CEO), appeared on the cover of Newsweek magazine, with a caption 'Can this man stop AIDS?'. IAVI's considered consultations and inputs into discussions about advanced purchase agreements for AIDS/HIV vaccines is probably best labelled policy-related advocacy. However one labels this type of activity, it is clearly different from the grassroots advocacy that many development initiatives claim to carry out. But IAVI has also been extremely active in 'grassroots advocacy' and participation activities. Indeed, in order to carry out clinical trials in different locations it has had to undertake groundwork prior to community involvement in vaccine trials. It educates about HIV/AIDS in general and always works in partnership with local grassroots organisations, and has worked closely with local non-governmental organisations 
(NGOs) and community-based health groups. It has a strong reputation for the integrity of its work at the grassroots level (Skolnik 2003; Chataway and Smith 2006). Although IAVI is clear about its mission of creating and distributing a vaccine, it is also clear that in order for it to fulfil its mission effectively, it must work in partnership with groups at all levels and in particular understand and work in conjunction with grassroots organisations. This is important in terms of broader institution building. IAVI is explicitly part of the broader communities in which it operates and its approach is in part influenced by those of the organisations it works with in different contexts.

IAVI has also invested very considerable amounts in infrastructure and in training in African countries and has contributed to capacity building in both Africa and India. We have provided detail about capacity building in other publications (Chataway and Smith 2006; Chataway et al. 2007a) but to summarise, IAVI has done the following:

- Built and refurbished laboratories including a state-of-the-art clinical unit at Uganda Viral Research Institute (UVRI) and substantially invested in the Kenya AIDS Vaccine Initiative's (KAVI) infrastructure and equipment.

- Created a large network of AIDS vaccine testing sites and the world's first consortium of laboratories for conducting validated HIV immune response assays.

- Provided funding for running expenses and the training and updating of scientists' and technicians' knowledge including ongoing training courses on Good Clinical Laboratory Practice (GCLP). IAVI works with a core laboratory in London to ensure that sites are able to follow GCLP. Training is carried out in London and in local laboratories.

In Africa, substantial amounts of money have been invested in infrastructure and in training (Chataway and Smith 2006). IAVI has worked with speed and efficiency, combining focused activity with real evidence of capacity building and engagement with Southern partners. Importantly, interviewees from Kenyan, Ugandan and Rwanda facilities all feel that largely as a result of engagement with IAVI, they have the potential of turning their units into clinical trials centres of excellence, dealing not only with HIV/AIDS vaccine but with a range of drug development projects. This is an unusual story of capacity building activity.
In India, where technological capacity is relatively advanced, there is still a need to provide access to the latest developments at an international level. In India (as in a number of other developing countries where IAVI is operational) a Memorandum of Understanding (MOU) exists with ministries and research institutes and close relationships with NGOs and private sector companies are also pursued. Considerable effort has been put into bringing together policymakers and private sector companies in discussion about the role that Indian institutions could play in research and development efforts and then in manufacturing efforts should a vaccine result.

\section{Communications-led strategy}

An interesting question is, why did IAVI pursue this strategy? Why did it not just focus on creating a vaccine in the best laboratories in the world and in the shortest time? Given the urgency of the challenge IAVI confronts, there would have been an argument for taking that approach. The answer is not simply that IAVI decided to be a good citizen in developing countries. The very hefty investment and the enormous effort involved in creating partnerships in developing countries, is not an 'add on' to other efforts so much as it is a consequence of taking communications extremely seriously and in some sense, letting the communication concerns drive the work. IAVI is an organisation driven and dominated by its concern with communication. And that has led it in interesting directions with some very interesting results.

As mentioned previously, IAVI is headquartered in New York. Importantly, the majority of IAVI's directors do not have research science backgrounds and a high proportion of IAVI managers have experience in advocacy and communications, many with a mix of private and public sector backgrounds.

IAVI began its work on vaccine development in Kenya. These efforts were in partnership with KAVI and the Oxford Medical Research Council laboratory and IAVI in New York. IAVI at that time did not have a regional office and could well be characterised at the time as a US- or 'Western'-led effort. This danger was highlighted by an independent review (Skolnik 2003). It quickly became apparent to IAVI that if it was to develop local support (which is absolutely essential if a vaccine is to be distributed effectively) it would have to work in such a way that it had local partnership at its core and prioritise local communications as well as lobbying efforts at the international level. 
As a consequence of this desire to build political demand and support from the grassroots level up, IAVI needed to make sure that efforts were seen as locally appropriate endeavours. The AIDS vaccine initiative needed to be owned by developing countries, and compromises and concessions to capacity building in developing countries had to be made. IAVI committed to that effort and let it influence the work it does in fundamental ways.

Commenting on the way in which operations were established in India, where a MOU was signed with two government bodies at the outset, one IAVI interviewee said:

It's a partnership with governments and we always accept that ... it's a three way partnership, NACO [the National AIDS Control Organization] and ICMR [the Indian Council of Medical Research] and us and we are the junior partners and we accept that'. The interviewee went on to talk about the importance of relationships with NGOs and civil society, both for operational purposes and in terms of legitimacy ...

'government told us quite early on that in India if there was significant opposition in civil society, it didn't really matter much what government wanted or didn't want, we wouldn't get to do it ... India is a democratic country and that's clear.

The strategy of combining advocacy, PR (IAVI's CEO, Seth Berkeley, meets regularly with India's political, community and medical leaders) and more participative approaches appears successful in this case. Close relationships have been forged with community groups and NGOs and the emphasis on advocacy and relationship building is noted by an independent reviewer as having been particularly strong. One informant noted, 'If IAVI had not come, India would not have taken a vaccine initiative so soon and so strongly'. Another said that 'vaccines would have been a non-issue (in India) without IAVI' (Skolnik 2003).

Apart from commitments to developing infrastructure in African countries, IAVI's communications focus has had other consequences. For example, in Africa, IAVI conceptualises the vaccine trials themselves as an advocacy programme. The trials provide a lot of publicity, drive state engagement, and provide people with the opportunity to begin to engage with issues around their fundamental needs, their rights with respect to biomedical ethics, and essentially drive African demand for a vaccine, at a political if not an economic level. This is an important component of IAVI's work on access to a vaccine should it become available. One interviewee from the East Africa regional office stated:

I bet you that is what he (interviewees' boss) is doing right now, that's why he is not in the office. He's sensitizing the community, and we define community very broadly, and sensitizing the community so that people are aware and people understand that people are aware and people understand that the vaccine does have a place in HIV prevention, and when it becomes available they will demand it from their governments and their governments will demand it at the United Nations, whatever forum is available to them to make these demands for an HIV vaccine. And it's not stored on the shelf somewhere.

The interviewee went on to say that this view of advocacy and trials as building demand was related to decisions to locate trial sites in different African countries rather than just concentrating efforts. 'Just being on the ground does create this awareness and hopefully ... in the end it will create this demand'.

IAVI's advocacy work and its role in stimulating awareness are widely acknowledged. An independent evaluation in 2003 said:

IAVI has helped to raise the political profile of HIV/AIDS. It has increased the attention of policy makers to the need for an AIDS vaccine that would meet the needs of developing countries and that would be available simultaneously throughout the world ... IAVI has begun to involve developing country policy makers, scientists, and civil society in AIDS vaccine efforts in essential ways in which they never involved before. While doing all of this, IAVI has also been the world leader in providing information on AIDS vaccines.

(Skolnik 2003)

Whether or not IAVI succeeds in its overall mission or is judged over the longer term as a success will of course depend on many factors. ${ }^{2}$ We would certainly not want to suggest that the IAVI approach is a blueprint or that it is guaranteed success. The sources of risk and uncertainty are of course both scientific 
and social; overall success will depend on many factors. Even if a vaccine does result, the ability to deliver and distribute it may well depend on having viable health systems in poor countries which do not currently enjoy even the basics of healthcare provision.

An emphasis on communications, spanning both public relations and advocacy, seem to have pushed IAVI in the direction of real engagement with partners in developing countries and to a broader approach to its partnerships than might have been expected. ${ }^{3}$ Of course, this engagement and participation is also fundamental to carrying out clinical trials. A strong communications strategy, based on the need to gain support has led to more participation. This is important to IAVI primarily because of 'productivity' concerns and yet there are very obvious 'entitlement' consequences and implications for various stakeholders.

We have suggested that because IAVI needs to communicate its message about HIV/AIDS and in arguing for the importance and possibility of a vaccine it has created to some extent a participative structure. The organisation needs to be seen to respond to the voice of many stakeholders. The success of its clinical trials work depends on the effectiveness in communicating clearly about the potential benefits of trials and the risks involved, and in ensuring the participation of people in trials work. It is held to account by states, NGOs, communitybased organisations (CBOs) and regulators with respect to the clinical trials works.

\section{Conclusions: reflections on innovation systems, exit voice and loyalty in IAVI}

IAVI is not trying to create an AIDS vaccine for developing countries simply by investing in science. While a great deal of its financial resource is devoted to the science, building routes through to market and addressing issues of acceptance of a vaccine are very high priorities. In this regard, IAVI's approach to vaccine development is certainly based on trying to address the problem of product development and acceptance from a more systemic approach. It is aware that it needs to consider production and distribution issues across the value chain. Additionally, because it is heavily monitored and relies on goodwill and consent-based engagement of clinical trials participants, IAVI needs to build community-based structures into its work. Feedback mechanisms and a non-linear approach to vaccine development are evident and from an innovation systems base all can be judged to be positive. However, there are a series of questions relating to innovation systems analysis that are unclear. These include the following.

What is the relationship between what IAVI does at the micro level and broader dynamics in different contexts? Is IAVI having an impact on the wider innovation and health systems environments?

What are the significant constraints and debates about IAVI in different contexts? Do the dynamics between participation at grassroots level and the overall communication strategies vary in different locations?

What are the properties and capacities within IAVI that allow it to act as a development actor and innovator? What are the tensions and is IAVI able to fully combine activities successfully? ${ }^{4}$

If there are unanswered questions about IAVI in relation to an innovation systems framework there are far more in relation to Hirschman's framework of exit, voice and loyalty and in relation to institutional development. Nevertheless, Hirschman's framework is useful because it offers a way to structure thoughts about the way participation may and may not relate to broader organisational and institutional change. While our thinking about the exit, voice and loyalty in relation to IAVI is schematic it does allow for a tentative story to emerge and provides the groundwork for more analytical and focused questions to be developed.

One of our main suggestions is that IAVI works to secure engagement (builds loyalty) because it needs to gain approval from many individuals, organisations and institutions at many levels. It operates under the threat of 'exit' by donors, partners and a wide range of collaborators and supporters in different contexts. Thus, it works to secure loyalty by creating a sophisticated communications strategy. To some extent, participation is explicitly addressed in a broader communications strategy, which values and needs to take seriously 'voice' from the grassroots and other organisations, this being a requisite from donors and collaborators. Channels within IAVI and IAVI's communication with others and IAVI's thinking about its relations with others are to some extent influenced by participation efforts. Here, it is important that IAVI is operational in a context where it is working in 
democracies and is heavily monitored by national and international bodies. Voice here has both productivity and entitlement consequences which are clearly intertwined but on the basis of this work and within the confines of this initial exploration this remains territory to be further investigated.

Exit is a very real option for individuals and organisations involved particularly in the clinical trials work and exit is to some extent perhaps enhanced by working to strengthen not only work in vaccines (where there are a very limited number of organisations and thus not much 'choice') but also for prevention and care. Thus, individuals and governments could opt to support other approaches

\section{Notes}

1 Other relevant categorisations have been developed by Agarwal (2001), Gaventa (2002) and Cornwall (2002)

2 Some consider that IAVI's approach to intellectual property whereby IAVI insists on having controlling rights over projects that it invests in will hamper its success in the long run. Whether or not it is true, it is important here to note that IAVI does stipulate boundaries within which communication takes place.

\section{References}

Agarwal, B. (2001) 'Participatory Exclusions, Community Forestry and Gender: An Analysis for South Asia and a Conceptual Framework', World Development 29.10: 1623-48

Chataway, Joanna and Smith, James (2007) 'Partnerships between CGIAR Centres and Civil Society Organisations', forthcoming report commissioned by the CGIAR Science Council

Chataway, Joanna; Brusoni, Stefano; Cacciatori, Eugenia; Hanlin, Rebecca and Orsenigo, Luigi (2007a) 'The International AIDS Vaccine Initiative $(\mathrm{IAVI})$ in a Changing Landscape of Vaccine Development: A Public Private Partnership as Knowledge Broker and Integrator', The European Journal of Development Research 19.1: 100-17

Chataway, Joanna; Hanlin, Rebecca; Rosiello, A. and Smith J. (2007b) 'Rethinking Vaccine R\&D in Developing Countries: Introduction to a Special Issue on Vaccines and Development', International Journal of Technology Management and Sustainable Development 6.1: 3-8 to the disease. Using our earlier distinction, we could say that IAVI is developing 'communication for participation' and this yields some positive impacts on its own organisational development and on broader institutional development. However, this a rosy picture and there may well be complications and contradictions in this story which have not fully come out in fieldwork to date. For example, in some instances, efforts to secure loyalty may actually block 'voice' and participation; 'spin' may take over from real engagement. It may also be that IAVI's dominance in some places may reduce 'exit' options - if IAVI is or comes to be seen as so dominant that it is not open to challenge, this may reduce people's willingness to engage and it may reduce IAVI's responsiveness.

3 In another article, we have also written about how IAVI's approach to technical communication between partners and the priority it gives to 'tacit' knowledge communication has resulted in capacity building (Chataway and Smith 2006).

4 We have begun to look at these issues in a recent publication: e.g. see Special Issue on Vaccines and Development of the International Journal of Technology Management and Sustainable Development (Chataway et al. 2007b: 6/1).

Chataway, Joanna and Smith, James (2006) 'The International AIDS Vaccine Initiative: Is it Getting New Science and Technology to the World's Neglected Majority?, World Development 43.1: 16-30

Cornwall, Andrea (2002) Beneficiary, Consumer, Citizen: Perspectives on Participation for Poverty Reduction, SIDA Studies 2, Stockholm: Swedish International Development Cooperation Agency

Gaventa, John (2002) 'Exploring Citizenship, Participation and Accountability', IDS Bulletin 33.2: $1-11$

Hall, Andy (2005) 'Capacity Development for Agricultural Biotechnology in Developing Countries: An Innovation Systems View of What it is and How to Develop it', Journal of International Development 17.5: 611-30

Hall, Andy; Bockett, Geoffrey; Clark, Norman; Sivamohan, M.V.K. and Taylor, Sarah (2001) 'Why Research Partnerships Really Matter: Innovation Theory, Institutional Arrangements and Implications for Developing New Technology for the Poor', World Development 29.5: 783-97 
Hickey, Samuel and Mohan, Giles (2004) Participation: From Tyranny to Transformation?, London: Zed Books

Hirschman, Albert (1970) Exit, Voice and Loyalty: Responses to Declines in Firms, Organizations and States, Cambridge: Harvard University Press Irwin, Alan and Wynne, Brian (2004)

Misunderstanding Science? The Public Reconstruction of Science and Technology, Cambridge: Cambridge University Press

Jasanoff, Sheila (2007) Designs on Nature: Science and Democracy in Europe and the United States,

Princeton: Princeton University Press

Leach, M.; Scoones, I. and Wynne, B. (2005) Science and Citizens: Globalization and the Challenge of Engagement, London: Zed Books

Lundvall, Bengt-Ake (1992) National Systems of Innovation: Towards a Theory of Innovation and Interactive Learning, London: Pinter

Metcalfe, Stanley (2005) Innovation, Competition and Enterprise: Foundations for Economic Evolution in
Learning Economies, CRIC Discussion Paper 71, Manchester: CRIC

Mina, Andrea; Metcalfe, Stanley; Ramlogan, Ronnie and Tampubolon, Gindo (2005) Networks of Knowledge: The Distributed Nature of Medical Innovation, CRIC Discussion Paper 74, Manchester: CRIC

Mohan, Giles (2007) 'Participatory Development: From Epistemological Reversals to Active Citizenship', Geography Compass 11.4: 779-96

Mosse, David (2005) Cultivating Development: An Ethnography of Aid Policy and Practice, London: Pluto Press

Skolnik, Richard (2003) Independent Evaluation of the International AIDS Vaccine Initiative, New York: International AIDS Vaccine Initiative (IAVI)

Tait, Joyce (2004) 'Science and Bias', paper presented at the BA Festival of Science, 6 September

Taverne, Dick (2005) The March of Unreason: Science, Democracy and the New Fundamentalism, Oxford: Oxford University Press 